\title{
PENGEMASAN PAKET WISATA CITY TOUR BERBASIS BUDAYA DI KOTA DENPASAR BALI
}

\author{
I Wayan Gede Ary Mahendra Putra \\ I Made Kusuma Negara \\ I Putu Sudana \\ Email : arymahendraputra1@gmail.com \\ PS . S1 Industri Perjalanan Wisata \\ Fakultas Pariwisata UNUD
}

\begin{abstract}
Denpasar city has a variety of tourist potential, namely the potential of cultural tourism such as historical buildings, art attractions, a traditional market with a wide variety of traditional dishes as well as community activities related to culture. Given these potentials can be developed into a tourist city tour packages in Denpasar. In connection with the travel package packing city tour, then the formulation of issues to be discussed are (1) What is the potential of the city of Denpasar as a cultural tourist attraction ?, (2) How packaging travel packages culture-based city tour in Denpasar? This study aims to determine the potential of the city of Denpasar as cultural charms, knowing the way of packaging travel packages culture-based city tour in the city of Denpasar. Data collection techniques in this study was done by observation, interview, and literature study.

The results of this study indicate that the city of Denpasar has tourism potential which comprise the majority of the potential of cultural tourism, the potential that made travel packages in this study is the charm of the castle and temple, traditional market and museum in the city of Denpasar The potential is then packaged in three forms, namely, in narrative form, tabular and graphical form four- travel packages including: Melali ke Puri, Heritage Denpasar City Tour, Beautiful Cultural of Denpasar City Tour, Historic Denpasar City Tour.
\end{abstract}

Keywords : Potency, Cultural Tour, Tour Package

\section{LATAR BELAKANG}

Bali dan Pariwisata adalah dua kata yang saling berkaitan dan sulit untuk dipisahkan. Pulau Bali yang berukuran hanya 0,3\% dari nusantara. Namun tidak disangka namanya lebih terkenal dibandingkan Indonesia. Kekhasan ini disebabkan oleh reputasi Pulau Bali sebagai "surga pariwisata" kini telah menjadi ikon promosi pariwisata baik di Indonesia maupun di dunia internasional. Segala macam atraksi, budaya, alam yang indah serta ritual Agama Hindu yang dimiliki oleh Bali dapat diibaratkan sebagai organ-organ penting yang menjiwai serta memajukan pariwisata Bali. Bali yang terbagi menjadi 8 kabupaten dan satu kotamadya banyak memiliki daerah tujuan wisata yang elok dan indah dengan ciri khas serta keunikannya. Masing-masing daerah menawarkan jenis pariwisata yang berbeda, seperti Kabupaten Gianyar yang lebih menonjolkan Pariwisata Pedesaan (Rural Tourism) beserta segala aktivitas keseharian masyarakatnya, Kabupaten Bangli, Jembrana, Tabanan, Buleleng, Karangasem dan Klungkung dengan Pariwisata Pertanian (Agrotourism), serta Kabupaten Badung dan Kota Denpasar yang didominasi oleh pariwisata yang bernuansa modernisasi.

Setiap daerah di Bali pasti memiliki keunikan adat tradisi serta ciri khas budayanya masing-masing. Namun, banyak orang beranggapan bahwa daerah perkotaan pasti telah banyak mengalami modernisasi dan mungkin sebagian lainnya berpikir bahwa budaya dan sejarah yang dimiliki kota tersebut sudah mulai ditinggalkan. Tak terkecuali Kota Denpasar, 
pernyataan inipun seakan-akan kian melekat erat setiap Kota Denpasar disebutkan. Untuk itu diperlukan suatu terobosan baru guna kembali memperkenalkan budaya serta sejarah yang dimiliki wilayah perkotaan, karena tidak dipungkiri banyak tempat di wilayah perkotaan yang masih kental dengan budaya dan sejarahnya yang belum terkelola secara profesional dan maksimal. Salah satu potensi pariwisata yang dimiliki Kota Denpasar adalah bangunan bersejarah, pura, puri, dan pasar tradisional dengan berbagai macam makanan tradisionalnya serta daya tarik pariwisata lainnya (web resmi Kota Denpasar). Untuk itu perlu adanya upaya revitalisasi guna mengangkat kembali pariwisata berbasis budaya di Kota Denpasar khususnya memperkenalkan kembali latar belakang dari Kota Denpasar ini sendiri. Di Kota Denpasar masih sangat jarang ditemukan adanya suatu paket wisata yang mencangkup nilai-nilai sejarah dan budaya, maka dari itu perlu di buatnya suatu rancangan mengenai pengemasan paket wisata city tour berbasis kebudayaan di Kota Denpasar.

\section{METODE}

Tinjauan pustaka yang digunakan adalah tinjauan tentang pariwisata dengan teori Suwantoro (1997), tinjauan tentang potensi wisata dengan teori Pendit (2002), tinjauan tentang paket wisata dengan teori Suyitno (2001), tinjauan tentang city tour dengan teori Page (2003), tinjauan tentang pariwisata budaya dengan teori Picard (2006), tinjauan tentang daya tarik wisata dengan teori Ismayanti (2010).

Teknik pengumpulan data yang digunakan yaitu dengan cara observasi, wawancara, studi kepustakaan. Teknik penentuan informan metode purposive sampling. Informannya yaitu orang pengelola dari masing-masing daya tarik wisata yang akan dikemas menjadi paket wisata city tour, pengusaha Biro Perjalanan wisata yang akan diikut sertakan dalam kerja sama untuk memasarkan paket wisata city tour serta pemandu wisata yang terlibat dalam interaksi paket wisata city tour Kota Denpasar serta tokoh masyarakat yang ada di masing-masing daya tarik wisata yang akan dikemas mejadi paket wisata city tour di Kota Denpasar.

\section{PEMBAHASAN}

Kota Denpasar memiliki potensi wisata yang terdiri atas potensi wisata budaya, dimana potensi yang dijadikan paket wisata dalam penelitian ini adalah pesona Puri Agung Satria Denpasar. Puri. Puri Agung Satria terdapat bangunan bersejarah peninggalan masa Belanda serta bangunan pendopo yang dipergunakan sebagai tempat pertemuan raja-raja seluruh Bali,

Puri Pemecutan memiliki keunikan pada arsitekturnya yang bergaya traditional Bali yang dibangun pada abad ke 16. Disebelah barat Puri terdapat gudang senjata (bedil) dan meriam yang digunakan saat masa peperangan.

Puri Kesiman memiliki potensi fisik seperti ciri khas dari puri tersebut adalah setiap halaman didalam lingkungan puri dihubungkan dengan candi bentar dan kori agung yang masih asli dari jaman kuno.

Kota Denpasar juga memiliki pesona pura sebagai potensi wisata seperti Pura Agung Jagatnatha dengan potensi fisiknya yaitu memiliki bangunan padmasana yang sangat tinggi dan merupakan pusat orientasi spiritual Kota Denpasar. Pura Petilan Pengrebongan memiliki potensi nonfisik seperti uniknya tradisi ngerebong saat upacara berlangsung.

Potensi lain yang dimiliki Kota Denpasar adalah adanya museum dan monumen seperti Museum Bali dengan potensi fisiknya menyimpan berbagai macam benda bersejarah seperti arca-arca. Museum Sidik Jari menyimpan lukisan dengan metode lukis menggunakan jari. Monumen Bajra Sandhi merupakan bangunan yang berbentuk genta., dalam monumen ini terdapat diorama yang menggambarkan Bali pada masa peperangan. Taman Budaya Art Center merupakan bangunan yang didirikan oleh gubernur pertama di Bali yaitu Ida Bagus Mantra dan dijadikan tempat berlangsungnya Pesta Kesenian Bali

Desa Budaya kertalangu memiliki potensi fisik seperti keindahan persawahan yang terletak ditengah-tengah kota. Taman Puputan Badung memiliki bukti sejarah, terjadi peperangan sampai tetes darah terakhir antara pasukan Belanda dengan masyarakat Bali. 
Pasar Tradisional Kumbasari pasar ini terdiri dari dua lantai yang menjual berbagai berbagai kebutuhan pokok dan untuk lantai dua menjual berbagai cendera mata khas Bali. Pasar burung dengan potensi fisiknya adalah tersedianya berbagai jenis peliharaan yang dijual, dan terdapat perkumpulan dengan nama "Asosiasi Pecinta Batu Mulia" yang menawarkan benda-benda unik dan antik. Kota Denpasar juga memiliki berbagai industri kreatif yang bisa dijadikan potensi wisata. Pengemasan paket wisata city tour ini dibuat berdasarksn potensi-potensi yang terdapat di Kota Denpasar seperti : Puri Agung Satria Denpasar, Puri Agung Kesiman, Puri Pemecutan, Pura Agung Jagatnatha, Pura Petilan, Museum Bali, Museum Sidik Jari, Monumen Bajra Sandhi, Taman Werdhi Budaya Art Center, Taman Puputan Badung, Desa Budaya kertalangu, Pasar Tradisional Kumbasari, Pasar Burung Satria. Paket Wisata ini terdiri dari tiga bentuk yaitu, bentuk uraian, bentuk tabel dan bentuk grafik dan terdiri atas empat paket wisata yaitu Melali ke Puri, Beautiful Cultural of Denpasar City Tour, Heritage City Tour, Historic Denpasar City Tour.

Dengan adanya potensi-potensi wisata budaya yang ada di Kota Denpasar dapat disusun dalam empat buah paket wisata budaya, yaitu Paket wisata Melali ke Puri, Paket wisata Heritage Denpasar City Tour, Paket wisata Beautiful Cultural of Denpasar City Tour, dan Paket Wisata Historic Denpasar City Tour. Masing - masing paket wisata tersebut kemudian dijelaskan dalam bentuk tabel dan grafik.

Tabel akan mejelaskan tentang rangkaian acara yang dilakukan wisatawan dalam perjalanan, grafik menjelaskan bentuk jalur perjalanan yang disertai jarak dan waktu tempuh, dan harga paket menjelaskan tentang harga paket yang disesuaikan dengan jumlah peserta dan jenis kendaraan.

Dari beberapa paket tersebut berikut penjelasan dari masing-masing paket wisata yang dikemas dalam bentuk tabel :

\begin{tabular}{|c|c|c|c|c|}
\hline Tempat & Waktu & Durasi & Acara & Keterangan \\
\hline Hotel/Kuta & 09.30 & $\begin{array}{c}30 \\
\text { menit }\end{array}$ & $\begin{array}{c}\text { Persiapan } \\
\text { memulai tour } \\
\text { (berangkat) }\end{array}$ & \\
\hline Puri Satria & 10.00 & $\begin{array}{c}30 \\
\text { menit }\end{array}$ & $\begin{array}{c}\text { Melihat } \\
\text { aktivitas } \\
\text { keluarga Puri } \\
\text { Satia }\end{array}$ & \\
\hline $\begin{array}{c}\text { Objek } \\
\text { Wisata } \\
\text { Pasar } \\
\text { Burung } \\
\text { Satria }\end{array}$ & 10.35 & $\begin{array}{c}60 \\
\text { menit }\end{array}$ & $\begin{array}{c}\text { Melihat } \\
\text { proses } \\
\text { pembentukan } \\
\text { batu mulia } \\
\text { dan bokor }\end{array}$ & $\begin{array}{c}\text { Dalam } \\
\text { proses } \\
\text { pembentukan } \\
\text { batu dan } \\
\text { bokor } \\
\text { wisatan ikut } \\
\text { terlibat }\end{array}$ \\
\hline $\begin{array}{c}\text { Koprasi } \\
\text { Krama Bali }\end{array}$ & 12.40 & $\begin{array}{c}60 \\
\text { menit }\end{array}$ & $\begin{array}{c}\text { Makan siang } \\
\quad \text { (lunch) }\end{array}$ & \\
\hline $\begin{array}{c}\text { Taman } \\
\text { Puputan } \\
\text { Badung }\end{array}$ & 13.50 & $\begin{array}{c}30 \\
\text { menit }\end{array}$ & $\begin{array}{c}\text { Wisatawan } \\
\text { mengelilingi } \\
\text { kawasan } \\
\text { Taman } \\
\text { Puputan } \\
\text { Badung }\end{array}$ & \\
\hline $\begin{array}{c}\text { Pasar } \\
\text { Tradisional } \\
\text { Kumbasari }\end{array}$ & 14.30 & $\begin{array}{c}60 \\
\text { menit }\end{array}$ & $\begin{array}{l}\text { Wisatawan } \\
\text { berbelanja } \\
\text { oleh-oleh } \\
\text { khas Bali }\end{array}$ & \\
\hline
\end{tabular}

Paket Wisata Melali ke Puri

Sumber : Penulis, 2016

Pada tabel tersebut dijelaskan perjalanan yang dilakukan wisatawan mulai dari kegiatan awal yang dimulai dari hotel hingga kembali ke hotel disertai durasi dan waktu. Paket wisata ini mengambil beberapa tempat yang memiliki sejarah menarik dan wisatawan dapat melihat aktivitas keluarga Puri Satria dalam melakukan kegiatan kebudayaan.

Bentuk tabel dari Paket Wisata Heritage City Tour dapat dilihat sebagai berikut : 


\begin{tabular}{|c|c|c|c|c|}
\hline Tempat & Waktu & Durasi & Acara & Keterangan \\
\hline Hotel/Kuta & 09.30 & $\begin{array}{c}30 \\
\text { menit }\end{array}$ & $\begin{array}{c}\text { Persiapan } \\
\text { memulai } \\
\text { tour } \\
\text { (berangkat) }\end{array}$ & \\
\hline $\begin{array}{c}\text { Pura } \\
\text { Jagatnatha }\end{array}$ & 10.00 & $\begin{array}{c}30 \\
\text { menit }\end{array}$ & $\begin{array}{c}\text { Mengelilin } \\
\text { gi kawasan } \\
\text { pura }\end{array}$ & $\begin{array}{c}\text { Wisatawan } \\
\text { wabjib } \\
\text { menggunakan } \\
\text { kain/selendan } \\
\text { g }\end{array}$ \\
\hline $\begin{array}{l}\text { Museum } \\
\text { Bali }\end{array}$ & 10.35 & $\begin{array}{c}30 \\
\text { menit }\end{array}$ & $\begin{array}{c}\text { Mengelilin } \\
\text { gi kawasan } \\
\text { Museum } \\
\text { Bali }\end{array}$ & \\
\hline $\begin{array}{c}\text { Sanggar } \\
\text { Seni Gases }\end{array}$ & 11.15 & $\begin{array}{c}30 \\
\text { menit }\end{array}$ & $\begin{array}{c}\text { Melihat } \\
\text { proses } \\
\text { pembuatan } \\
\text { patung/ogo } \\
\text { h-ogoh }\end{array}$ & $\begin{array}{c}\text { Dalam proses } \\
\text { pembuatan } \\
\text { wisatawan } \\
\text { ikut terlibat }\end{array}$ \\
\hline $\begin{array}{c}\text { Jebak (Jejak } \\
\text { Kuliner } \\
\text { Bali) }\end{array}$ & 12.00 & $\begin{array}{c}60 \\
\text { menit }\end{array}$ & $\begin{array}{c}\text { Makan } \\
\text { siang } \\
\text { (lunch) }\end{array}$ & \\
\hline $\begin{array}{c}\text { Puri } \\
\text { Pemecutan }\end{array}$ & 13.20 & $\begin{array}{c}30 \\
\text { menit }\end{array}$ & $\begin{array}{c}\text { Mengelilin } \\
\text { gi kawasan } \\
\text { Puri }\end{array}$ & \\
\hline $\begin{array}{c}\text { Pasar } \\
\text { Tradisional } \\
\text { Kumbasari }\end{array}$ & 14.00 & $\begin{array}{c}60 \\
\text { menit }\end{array}$ & $\begin{array}{c}\text { Berbelanja } \\
\text { oleh-oleh } \\
\text { khas Bali }\end{array}$ & \\
\hline
\end{tabular}

Sumber : Penulis, 2016

\section{Paket Wisata Heritage City Tour}

Pada tabel tersebut dijelaskan perjalanan yang dilakukan wisatawan mulai dari kegiatan awal yang dimulai dari hotel hingga kembali ke hotel disertai durasi dan waktu. Paket wisata ini mengunjungi tempat yang menyimpan bendabenda bersejarah dan mengunjungi industri pembuat ogoh-ogoh dan patung, sehingga wisatawan mempunyai pengalaman yang menarik.

Bentuk tabel Paket Wisata Beautiful Cultural of Denpasar City Tour dapat dilihat sebagai berikut :

\begin{tabular}{|c|c|c|c|c|}
\hline Tempat & Waktu & Durasi & Acara & Keterangan \\
\hline Hotel/Kuta & 09.00 & $\begin{array}{c}30 \\
\text { menit }\end{array}$ & $\begin{array}{l}\text { Persiapan } \\
\text { memulai } \\
\text { tour } \\
\text { (berangkat) }\end{array}$ & \\
\hline $\begin{array}{c}\text { Barong and } \\
\text { Keris } \\
\text { Dance }\end{array}$ & 09.30 & $\begin{array}{c}60 \\
\text { menit }\end{array}$ & $\begin{array}{c}\text { Menyaksik } \\
\text { an } \\
\text { pementasan } \\
\text { Barong dan } \\
\text { Keris }\end{array}$ & \\
\hline Pura Petilan & 10.35 & $\begin{array}{c}30 \\
\text { menit }\end{array}$ & $\begin{array}{c}\text { Mengelilin } \\
\text { gi kawasan } \\
\text { Pura }\end{array}$ & $\begin{array}{c}\text { Wisatawan } \\
\text { wabjib } \\
\text { menggunakan } \\
\text { kain/selendang }\end{array}$ \\
\hline $\begin{array}{c}\text { Puri } \\
\text { Kesiman }\end{array}$ & 11.10 & $\begin{array}{c}30 \\
\text { menit }\end{array}$ & $\begin{array}{c}\text { Mengelilin } \\
\text { gi kawasan } \\
\text { Puri }\end{array}$ & \\
\hline $\begin{array}{l}\text { Pengrajin } \\
\text { Suling dan } \\
\text { Rebab }\end{array}$ & 11.45 & $\begin{array}{c}30 \\
\text { menit }\end{array}$ & $\begin{array}{c}\text { Melihat } \\
\text { proses } \\
\text { pembuatan } \\
\text { suling dan } \\
\text { rebab }\end{array}$ & $\begin{array}{c}\text { Dalam proses } \\
\text { pembuatan } \\
\text { wisatawan ikut } \\
\text { terlibat }\end{array}$ \\
\hline $\begin{array}{c}\text { Desa } \\
\text { Budaya } \\
\text { Kertalangu }\end{array}$ & 12.30 & $\begin{array}{c}150 \\
\text { menit }\end{array}$ & $\begin{array}{c}\text { Makan } \\
\text { siang, } \\
\text { menikmati } \\
\text { berbagai } \\
\text { zona dan } \\
\text { berbelanja } \\
\text { oleh-oleh } \\
\text { khas bali }\end{array}$ & \\
\hline
\end{tabular}

\section{Paket Wisata Denpasar City Tour}

\section{Sumber : Penulis, 2016}

Pada tabel tersebut dijelaskan perjalanan yang dilakukan wisatawan mulai dari kegiatan awal yang dimulai dari hotel hingga kembali ke hotel disertai durasi dan waktu. Paket wisata ini menyajikan produk seni dan budaya serta proses kegiatannya yang menggambarkan kegiatan kebudayaan.

Bentuk tabel Paket Wisata Historic Denpasar City Tour dapat dilihat sebagai berikut 


\begin{tabular}{|c|c|c|c|c|}
\hline Tempat & Waktu & Durasi & Acara & Keterangan \\
\hline Hotel/Kuta & 09.30 & $\begin{array}{c}30 \\
\text { menit }\end{array}$ & $\begin{array}{c}\text { Persiapan } \\
\text { memulai } \\
\text { tour } \\
\text { (berangkat) }\end{array}$ & \\
\hline Art Center & 10.00 & $\begin{array}{c}30 \\
\text { menit }\end{array}$ & $\begin{array}{l}\text { Mengelilin } \\
\text { gi kawasan } \\
\text { Art Center }\end{array}$ & \\
\hline $\begin{array}{c}\text { Pengrajin } \\
\text { Wadah/Petu } \\
\text { langan }\end{array}$ & 10.50 & $\begin{array}{c}30 \\
\text { menit }\end{array}$ & $\begin{array}{c}\text { Melihat } \\
\text { proses } \\
\text { pembuatan } \\
\text { wadah/petu } \\
\text { langan }\end{array}$ & $\begin{array}{c}\text { Dalam proses } \\
\text { pembuatan } \\
\text { wisatawan } \\
\text { ikut terlibat }\end{array}$ \\
\hline $\begin{array}{l}\text { Museum } \\
\text { Sidik Jari }\end{array}$ & 11.35 & $\begin{array}{c}30 \\
\text { menit }\end{array}$ & $\begin{array}{c}\text { Mengelilin } \\
\text { gi Museum } \\
\text { Sidik Jari }\end{array}$ & \\
\hline $\begin{array}{l}\text { Bajra } \\
\text { Sandhi }\end{array}$ & 12.10 & $\begin{array}{c}30 \\
\text { menit }\end{array}$ & $\begin{array}{c}\text { Mengelilin } \\
\text { gi } \\
\text { monument } \\
\text { Bajra } \\
\text { Sandhi }\end{array}$ & \\
\hline $\begin{array}{l}\text { Warung Be } \\
\text { Sanur }\end{array}$ & 12.45 & $\begin{array}{c}60 \\
\text { menit }\end{array}$ & $\begin{array}{c}\text { Makan } \\
\text { siang (lunh) }\end{array}$ & \\
\hline $\begin{array}{c}\text { Pasar } \\
\text { Tradisional } \\
\text { Kumbasari }\end{array}$ & 14.00 & $\begin{array}{c}60 \\
\text { menit }\end{array}$ & $\begin{array}{c}\text { Berbelanja } \\
\text { oleh-oleh } \\
\text { khas Bali }\end{array}$ & \\
\hline
\end{tabular}

Paket Wisata Historic Denpasar City Tour Sumber : Penulis, 2016

Pada tabel tersebut dijelaskan perjalanan yang dilakukan wisatawan mulai dari kegiatan awal yang dimulai dari hotel hingga kembali ke hotel disertai durasi dan waktu. Paket wisata ini mengunjungi beberapa daya tarik wisata yang berkaitan dengan sejarah dan budaya Bali. grafik.
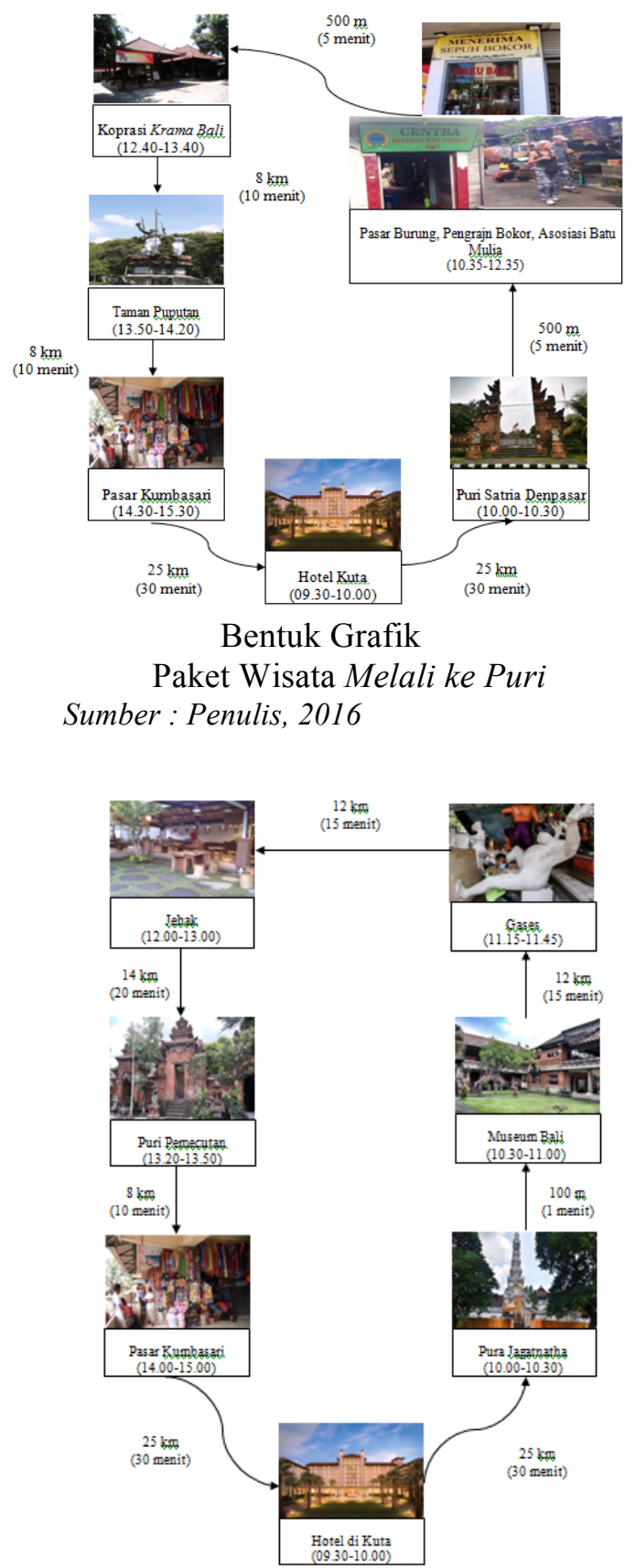

Bentuk Grafik

Paket Wisata Heritage City Tour Sumber : Penulis, 2016 


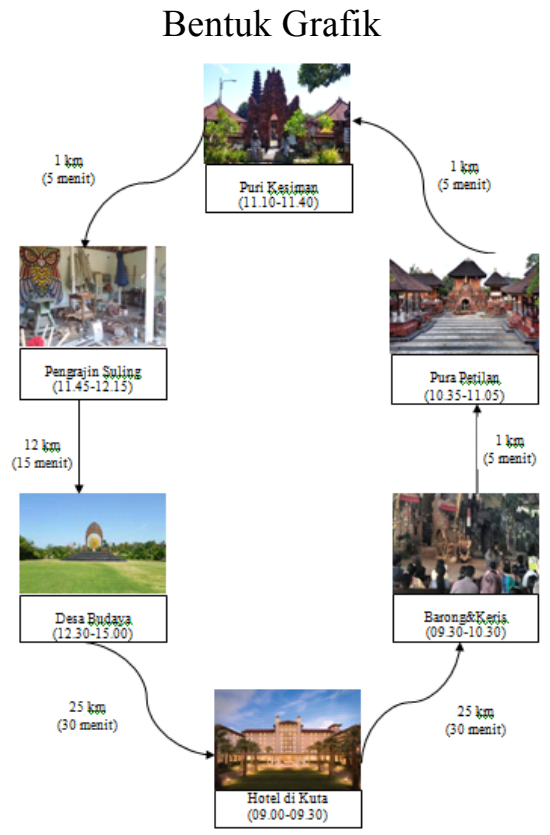

Paket Wisata Beautiful Cultural of Denpasar City Tour

Sumber : Penulis, 2016

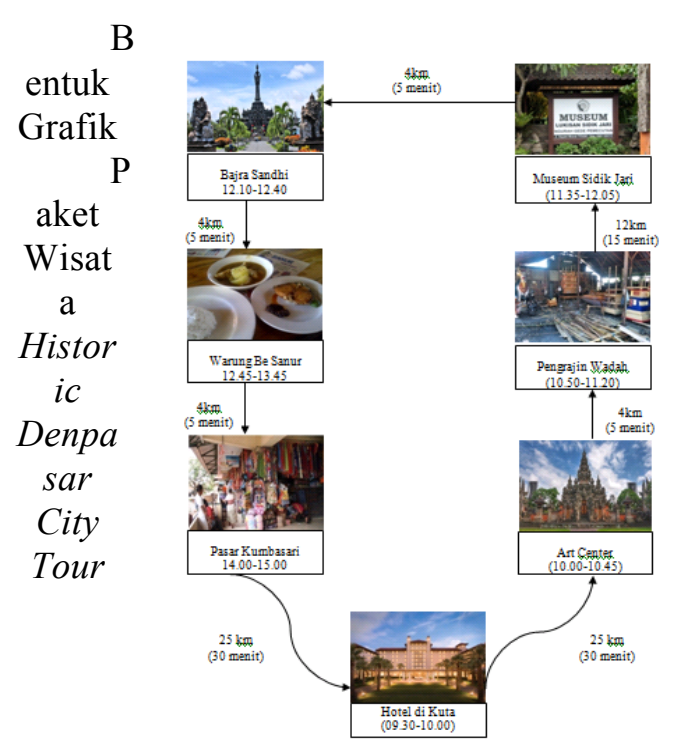

Sumber : Penulis, 2016

Dalam bentuk grafik dijelaskan bahwa bentuk jalur yang akan ditempuh oleh wisatawan selama perjalanan. Selain itu, grafik juga dilengkapi dengan waktu dan jarak tempuh menuju daya tarik yang tertera di paket wisata, antar daya tarik wisata dalam masing-masing paket.

\section{SIMPULAN DAN SARAN}

Simpulan

Berdasarkan hasil dan pembahsaan tentang pengemasan paket wisata city tour di Kota Denpasar dapat disimpulkan sebagai berikut :

1. Destinasi wisata berbasis budaya di kota denpasar diantaranya Puri Agung Satria Denpasar, Puri Agung Kesiman, Puri Pemecutan, Pura Agung Jagatnatha, Pura Petilan, Museum Bali, Museum Sidik Jari, Monumen Bajra Sandhi, Taman Werdhi Budaya Art Center, Taman Puputan Badung, Desa Budaya kertalangu, Pasar Tradisional Kumbasari, Pasar Burung Satria.

2. Terbentuk 4 jenis paket wisata dalam penelitian ini diantaranya empat paket wisata yaitu Paket Wisata Melali ke Puri, Paket Wisata Beautiful Cultural of Denpasar City Tour, Paket Wisata Heritage City Tour, Paket Wisata Historic Denpasar City Tour.

Saran

Tertakit dengan simpulan yang dikemukakan, adapun beberapa saran yang kiranya berguna bagi pengembangan wisata city tour di Kota Denpasar yaitu :

1. Pemerintah dan pelaku wisata diharapkan untuk saling berkoordinasi dan melihat potensi yang ada agar mampu menggalakkan serta membuat paket wisata city tour yang lebih menarik sehingga tidak muncul kejenuhan pada paket-paket wisata yang sudah ada. 
Vol. 4 No. 1, 2016

2. Menjaga kebersihan daya tarik wisata city tour agar menciptakan keindahan sehingga memberikan kesan positif terhadap wisatawan yang berkunjung ke daya tarik wisata tersebut.

\section{DAFTAR PUSTAKA}

Law, Christopher M. (1996): Tourism in Major Cities, International Thomson Business Press, London.

Picard, M. 2006. Bali: Pariwisata Budaya dan Budaya Pariwisata. Jakarta: KPG (Kepustakaan Populer Gramedia). 